\title{
A statistical survey of dayside pulsed ionospheric flows as seen by the CUTLASS Finland HF radar
}

\author{
K. A. McWilliams, T. K. Yeoman, G. Provan \\ Department of Physics and Astronomy, Leicester University, University Road, Leicester LE1 7RH, UK
}

Received: 10 September 1999 / Revised: 3 December 1999 / Accepted: 6 December 1999

\begin{abstract}
Nearly two years of 2-min resolution data and 7- to 21-s resolution data from the CUTLASS Finland HF radar have undergone Fourier analysis in order to study statistically the occurrence rates and repetition frequencies of pulsed ionospheric flows in the noon-sector high-latitude ionosphere. Pulsed ionospheric flow bursts are believed to be the ionospheric footprint of newly reconnected geomagnetic field lines, which occur during episodes of magnetic flux transfer to the terrestrial magnetosphere - flux transfer events or FTEs. The distribution of pulsed ionospheric flows were found to be well grouped in the radar field of view, and to be in the vicinity of the radar signature of the cusp footprint. Two thirds of the pulsed ionospheric flow intervals included in the statistical study occurred when the interplanetary magnetic field had a southward component, supporting the hypothesis that pulsed ionospheric flows are a reconnection-related phenomenon. The occurrence rate of the pulsed ionospheric flow fluctuation period was independent of the radar scan mode. The statistical results obtained from the radar data are compared to occurrence rates and repetition frequencies of FTEs derived from spacecraft data near the magnetopause reconnection region, and to ground-based optical measurements of poleward moving auroral forms. The distributions obtained by the various instruments in different regions of the magnetosphere were remarkably similar. The radar, therefore, appears to give an unbiased sample of magnetopause activity in its routine observations of the cusp footprint.
\end{abstract}

Key words: Magnetospheric physics (magnetosphereionosphere interactions; plasma convection; solar windmagnetosphere interactions)

Correspondence to: K. A. McWilliams

e-mail: k.mcwilliams@ion.le.ac.uk

\section{Introduction}

Magnetic reconnection is a fundamental process in the dynamics of the magnetosphere. The merging of the interplanetary magnetic field (IMF) and the geomagnetic field on the dayside provides the primary mechanism for energy input to the cyclic system (Dungey, 1961). Understanding the nature of this reconnection process is a key to revealing the true nature of the solar wind-magnetosphere-ionosphere interaction.

The first published observations consistent with episodic bursts of reconnection at the magnetopause were made at the magnetopause on board the Heos 2 satellite by Haerendel et al. (1978), who discussed a number of potential physical mechanisms of mass and momentum transfer from the solar wind to the magnetosphere. Evidence of pulsed reconnection at the magnetopause has been reported as a bipolar signature in the magnetic field component normal to the magnetopause (Haerendel et al., 1978; Russell and Elphic, 1978, 1979; Lockwood and Wild, 1993; Kuo et al., 1995).

Ground-based evidence of magnetopause reconnection followed when Goertz et al. (1985) used the STARE radar (Greenwald et al., 1978) to detect antisunward flow poleward of the convection reversal boundary with an occasional significant north-south component, as well as sporadic flow across the convection reversal boundary with scale sizes of 50 to $300 \mathrm{~km}$ and repetition rates of the order of minutes. These types of flows are consistent with the predicted response of the ionosphere to reconnection events at the magnetopause. Simultaneous spacecraft and ground-based observations of the reconnection region and its footprint, which are difficult to achieve, have since shown that the ionosphere does respond to FTEs and that the response is detectable as periodic anti-sunward ionospheric convective flow bursts (Elphic et al., 1990; Moen et al., 1995; Yeoman et al., 1997; Neudegg et al., 1999).

Since the relationship between magnetopause reconnection and its ionospheric response was established, 
many low-altitude studies have examined the nature of the ionospheric response to reconnection, and from this have attempted to make inferences about the nature of reconnection itself. Pulsed ionospheric flows (PIFs) have been observed in several frequency bands of radar data: UHF (Van Eyken et al., 1984), VHF (Goertz et al., 1985), and HF (Pinnock et al., 1995; Provan et al., 1998, 1999). Provan et al. (1999) produced a statistical study of the location and extent of PIFs seen by an HF radar. They found that the change in the ionospheric convection due to magnetic reconnection, periodic high-velocity anti-sunward bursts along the throat of the convection pattern, was in accordance with the average east-west IMF controlled tilt of the throat flow. Series of poleward moving auroral forms (PMAFs) at the polar cap boundary are believed to be the optical manifestation in the ionosphere of magnetospheric FTEs (Vorobjev et al., 1975; Sandholt et al., 1990, 1992; Fasel, 1995; Øieroset et al., 1997). Karlson et al. (1996) found an asymmetric prenoon-postnoon occurrence distribution of PMAFs which was highly dependent on the IMF $B_{y}$ component. Data from an HF radar, an all-sky camera, photometers, and an HF riometer have been compared and good agreement has been found between the various ground-based signatures of FTEs (Rodger et al., 1995).

Theoretical considerations of FTEs have resulted in suggestions for the possible cause of episodic bursts of reconnection at the magnetopause and in a description of their behaviour, both at the reconnection site and at their ionospheric footprint (Cowley, 1984; Siscoe and Huang, 1985; Cowley et al., 1991, 1992; Cowley and Lockwood, 1992; Lockwood, 1993; Lockwood et al., 1995; Lockwood and Hapgood, 1998). Hypotheses regarding the triggering mechanism, which predict separation times for FTEs from several to a few tens of minutes, include IMF $B_{z}$ fluctuations (Lockwood et al., 1989), spontaneous FTEs (Lockwood and Wild, 1993), and intrinsic magnetospheric system control (Kuo et al., 1995).

In general, low-altitude measurements have shown that, on a case-by-case basis, dayside ionospheric processes can be related directly to reconnection at the magnetopause. In situ studies of reconnection are, by definition, difficult to achieve. HF radars offer routine observations and excellent coverage of the ionospheric footprint of the reconnection region, but do ionospheric measurements offer an unbiased sample of magnetopause reconnection? The aim of the current research is to examine quantitatively a large sample of PIFs seen by an HF radar in the magnetic local noon sector. A technique based on Fourier analysis has been employed to determine the time between successive PIFS, and the resulting distribution is compared with results obtained from in situ measurements of FTEs and with ground-based measurements of PMAFs. This comparison enables a determination of whether PIFs observed by HF radars in the noon-sector high-latitude ionosphere are representative of magnetopause activity. If this is so, the PIFS, which are measured routinely by HF radars and offer routine, large-scale observations of the projection of the reconnection region, can be used to study the phenomenon of dayside magnetic reconnection.

\section{Observations}

The velocity data used in this study were obtained from the Co-operative UK Twin Located Auroral Sounding System (CUTLASS) (Milan et al., 1997), a pair of pulsed monostatic HF radars located in Iceland and Finland. The radars are a part of the international Super Dual Auroral Radar Network (SuperDARN) (Greenwald et al., 1995), which covers a large portion of the northern and southern auroral zones and polar caps. The SuperDARN radars measure high latitude plasma convection in the Northern and Southern Hemispheres at E-region and F-region altitudes.

During the common mode of operation the radars step through a series of 16 consecutive beam positions. The beam is produced by an array of sixteen log-periodic antennas and an electronically controlled phasing matrix, which steers the radar beam through its 16-position scan. The transmission sequence for the radars is a multipulse pattern. In standard operations the radars have a range resolution of $45 \mathrm{~km}$. In normal operations the radars run between 9 and $14 \mathrm{MHz}$ (measuring ionospheric irregularities between 10 and $17 \mathrm{~m}$ ), often changing their frequency between day and night depending on the ionisation of the $\mathrm{F}$ region, giving a typical angular resolution of $4^{\circ}$ or a half-power beam width of about $100 \mathrm{~km}$ at the half-range mark of $1500 \mathrm{~km}$. The multi-pulse sequence used in the SuperDARN common mode of operation consists of seven pulses sent out during a $100 \mathrm{~ms}$ transmission window. The dwell time for each beam is $7 \mathrm{~s}$, resulting in a 2-min scan time for the entire field of view. In high-time resolution mode fewer beams are scanned more frequently, or the dwell time is reduced, or both. This makes it possible to reduce the time resolution for a beam to one second. In the hightime resolution data used in the current study, the temporal resolution along a beam has been reduced from 2 min to 7-21 s, depending on the scan mode.

\section{Data analysis}

Studies of pulsed ionospheric flows have generally relied on visual event-by-event analysis of hand-picked data. For this study, an attempt was made to devise an objective, quantitative method to analyse PIFs. The technique utilises the Fourier transform to determine the dominant repetition frequencies in the noon-sector ionospheric convection.

\subsection{Selecting the PIF intervals}

PIFs are most easily identified in the CUTLASS radar line-of-sight (LOS) velocity data as periodic high velocity stripes moving away from the radar into the polar cap, often at speeds of the order of $1 \mathrm{~km} \mathrm{~s}^{-1}$. The 

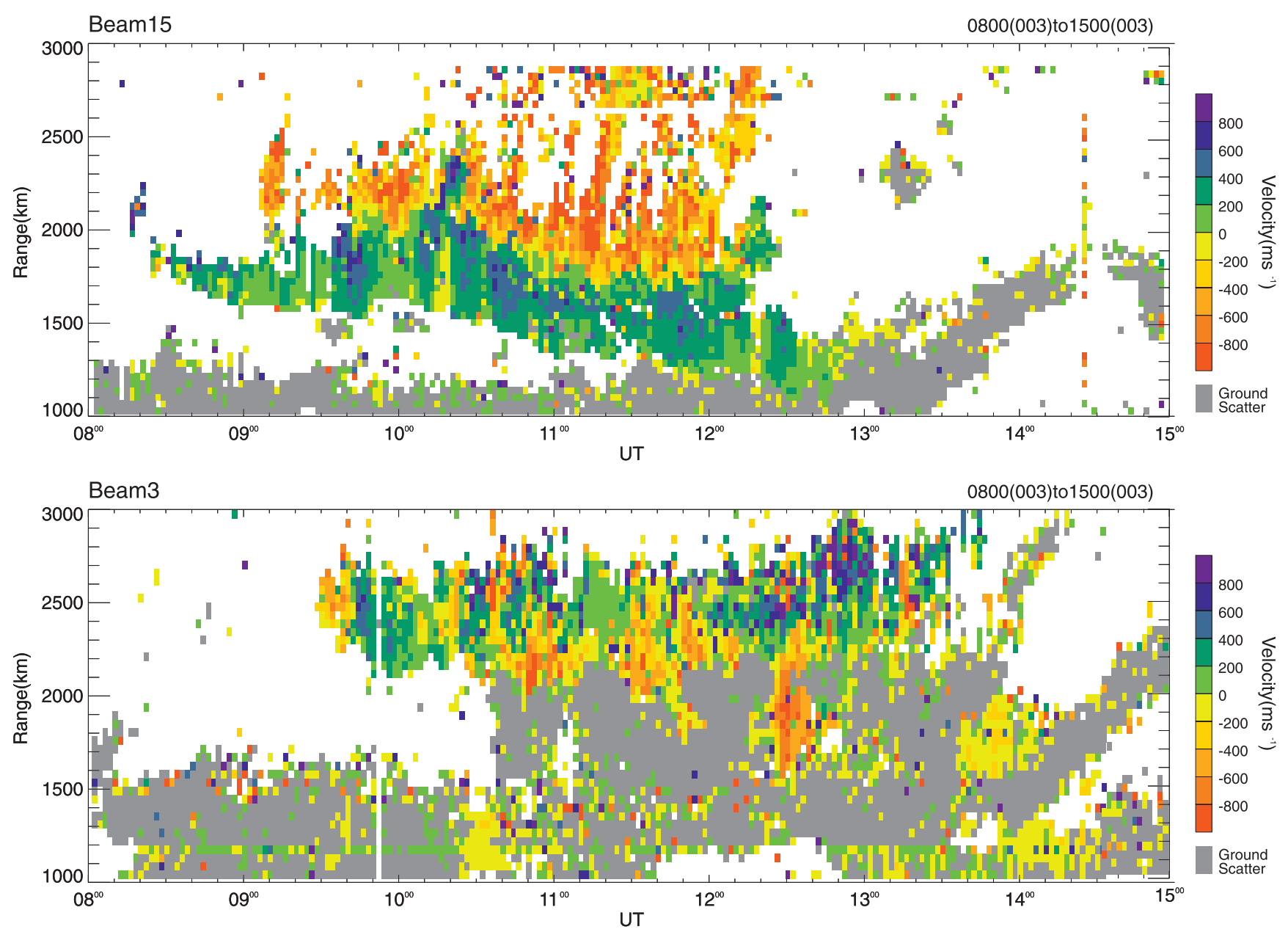

Fig. 1. Line-of-sight velocity data measured by CUTLASS Finland radar beams 15 and 3 between 08:00 and 15:00 UT on 3 January, 1996. Poleward-moving flow bursts are evident as the red

top panel in Fig. 1 is a typical example of periodic antisunward flow bursts seen in HF radar data. These data were measured by beam 15 (the easternmost beam) of the CUTLASS Finland radar between 08:00 and 15:00 UT on 3 January, 1996, one of the intervals included in the statistical study. In this range-time-velocity plot ground scatter is coloured grey, while the ionospheric scatter is represented by the colour scale on the right. Negative velocities (the yellow and red portion of the colour bar) signify plasma motion away from the radar. The identification of high-speed flow bursts such as these has been the most commonly used method to identify pulsed cusp footprint signatures in the radar data in previous studies of the ionospheric footprint of the magnetospheric cusp (e.g. Pinnock et al., 1995; Rodger and Pinnock, 1997; Provan et al., 1998; Neudegg et al., 1999).

The measured signal of the poleward-moving flow bursts depends on the direction of the plasma flow with respect to the radar beam direction. The high-velocity stripes described are the signature of a strong, periodic flow component away from the radar. As the plasma flow direction becomes less beam-aligned the measured signature of the PIFs becomes less evident. This effect is stripes seen in the data from beam 15 (top). Periodic velocity fluctuations also exist in the beam 3 data (bottom), but they are not so visually obvious

manifested in a decrease in the flow velocity and range extent of the PIFs along the radar beam, and in less distinction between flow pulses. The backscatter measurements made along beam 3, which is in the western portion of the CUTLASS Finland radar, are presented in the bottom panel of Fig. 1. These are the measurements taken at the same time as the high-velocity stripes are seen in the easternmost beam in the radar field of view. Velocity perturbations are present in the data from beam 3, but they are not so visually obvious as those measured along beam 15 . In order to study the extent of the PIF, it is therefore necessary to devise a quantitative method for finding periodicities in the plasma flow that may not look like the typical high-velocity flow bursts seen moving away from the radar.

The intervals selected for this statistical survey of PIFs were taken from CUTLASS Finland data measured between March 1995 and September 1996, inclusive. The flows occurred in the dayside ionosphere within several hours of magnetic local noon. Both high time resolution data ( 7 to $21 \mathrm{~s}$ dwell time per beam, depending on the scan pattern) and common mode ( 2 min resolution) data were studied, since both scanning modes have high enough resolution to detect PIFs 
(Provan and Yeoman, 1999). LOS velocity data were selected by an initial visual inspection of dayside measurements from all radar beams. This preliminary survey revealed 239 intervals with visually apparent variable flows on at least one radar beam. The high-time resolution data, selected in the same manner included 60 intervals, comprising 149 hours of radar data.

Once an interval was identified based on the PIF signatures in the LOS data, it was necessary to check that the data was measured in the vicinity of the cusp footprint. The geographic projection of a single radar scan measured between 10:42 and 10:44 UT on 3 January, 1996 is presented in Fig. 2. The line of sight velocity is plotted in Fig. 2a and the spectral width in Fig. 2b. The line-of-sight velocity plot has the same colour scale as the range-time-velocity plot in Fig. 1, where negative velocities denote flow away from the 3Jan1996

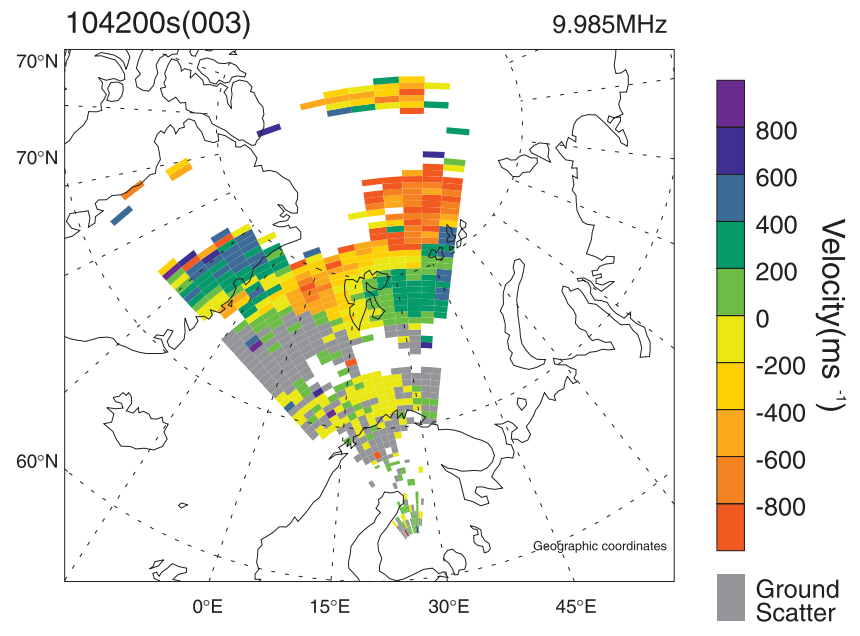

(b)

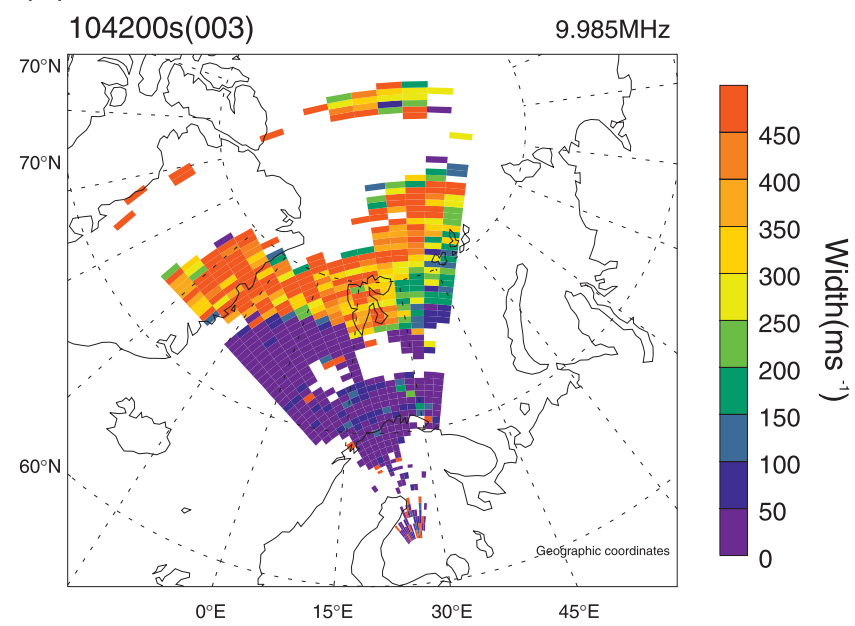

Fig. 2. a The single-scan line-of-sight velocity data measured by the CUTLASS Finland radar between 10:42 and 10:44 UT, 3 January, 1996. The co-ordinates are geographic and the colour scale is such that negative velocities (red-yellow) signify motion away from the radar. b The single-scan spectral width plot from 10:42 to 10:44 UT, 3 January, 1996 radar. The flow components toward the radar in the west and away from the radar in the east are consistent with eastward flow across the radar field of view. The high-latitude red stripes that were evident in the top panel of Fig. 1 correspond to the red patches originating in the centre of the field of view and extending to far ranges in the easternmost beams. The IMF for this interval had a $B_{z}$ component of about $-2 \mathrm{nT}(\mathrm{GSM})$ and a $B_{y}$ component of about $-4 \mathrm{nT}$ (GSM), measured by the WIND spacecraft magnetic field instrument (Lepping et al., 1995). WIND was located approximately 170 Earth radii upstream. The strong duskward flows away from the radar are consistent with the negative $B_{y}$ component. The spectral width of the CUTLASS measurements can be used to estimate the location of the ionospheric footprint of the magnetospheric cusp. In the radar data the cusp footprint is identified as having a complex Doppler spectrum and a broad spectral width distribution (Baker et al., 1995). The high spectral widths (above $400 \mathrm{~m} \mathrm{~s}^{-1}$ ) are found above approximately $75^{\circ}$ in Fig. 2b. The flow toward the radar at medium ranges in the east coincides with a region of narrow spectral widths. This is consistent with the lower latitude sunward return flow on closed field lines. The ground scatter at lower latitudes is also characterised by narrow spectral widths.

\subsection{Fourier analysis}

To quantify the periodic fluctuations in the hand picked data, a Fourier transform (FFT) was applied to the time series for each range cell in the radar field of view. The Fourier analysis of the time series required some pretransform processing: linear trends in the velocity data were removed, the time series were shifted in order to have a zero mean value, and the ends of the time series were tapered using a cosine bell curve.

Figure $3 \mathrm{a}$ is the LOS velocity time series measured at range 52 of beam 15 between 9:30 and 12:30 UT on 3 January, 1996. Strong bursts of flow away from the radar (negative Doppler shifts) are evident. Figure $3 \mathrm{~b}$ is the resulting Fourier spectrum of the time series in Fig. 3a. The spectrum has been normalised to the peak value, which occurs at approximately $0.09 \mathrm{mHz}$. The equivalent period for this frequency is about $189 \mathrm{~min}$ and corresponds to the duration of the time series. In an attempt to ensure a good velocity sample with few data gaps, an FFT was calculated only if more than $20 \%$ of the possible data points in the time series existed. This value was chosen in order to accommodate the geometric effects of the large-scale radar measurements. As the radar rotates into the noon sector, the eastern beams measure the PIFs first while the western beams generally measure no backscatter. The reverse occurs as the radar moves out of the noon sector. The repetition frequencies in the Fourier spectrum were considered to be significant when their power exceeded five percent of the maximum power. The equivalent periods that are above the 5\% minimum power threshold in Fig. $3 \mathrm{~b}$ occur at about $189,41,12,9,8$, and $5 \mathrm{~min}$. 

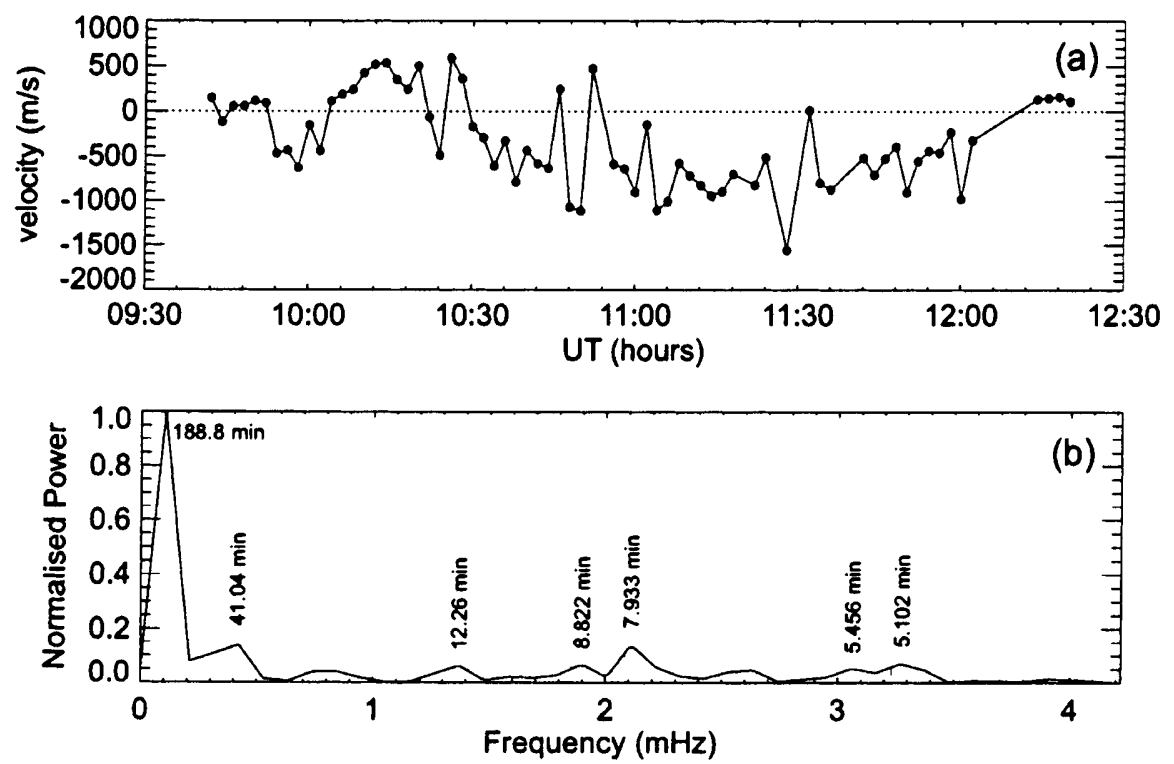

Fig. 3. a The CUTLASS velocity time series from beam 15 , range 52 on 3 January, 1996, between 09:30 and 12:30 UT. b The Fourier spectrum of CUTLASS velocity time series in a normalised to the peak power. Fluctuations above the 5\% minimum normalised power threshold occur at approximately 189, 41, 12, 9, 8, and 5 min
In order to facilitate comparison with other data sets (Lockwood and Wild, 1993; Kuo et al., 1995; Fasel, 1995), which have dealt with the time between successive FTEs or PMAFs, the oscillation frequencies from the FFT analysis of the time series were converted to repetition periods, in minutes. The distribution within the radar field of view of the resulting repetition periods for each interval were then investigated. Figure 4 presents an example of the distribution of the fluctuation period over the radar field of view. These have been deduced from the FFT of the 09:30-14:00 UT time series on 3 January, 1996. Each plot represents the spatial distribution of significant fluctuations, as defined already, within a $1 \mathrm{~min}$ interval. For example, the top left plot shows the range cells where such periodicities, $T$, were found in the field of view such that $4.0 \mathrm{~min} \leq$ $T<5.0 \mathrm{~min}$. The plot to its right shows where $5.0 \mathrm{~min} \leq T<6.0 \mathrm{~min}$, and so on. The grey range cells are where the FFT analysis has found significant periodicities within the specified one-minute interval, as defined above. Range cells where the FFT spectrum is calculable but there are no significant spectral peaks within the stated range are coloured black. In Fig. 4 there is a very clear grouping of range cells with similar
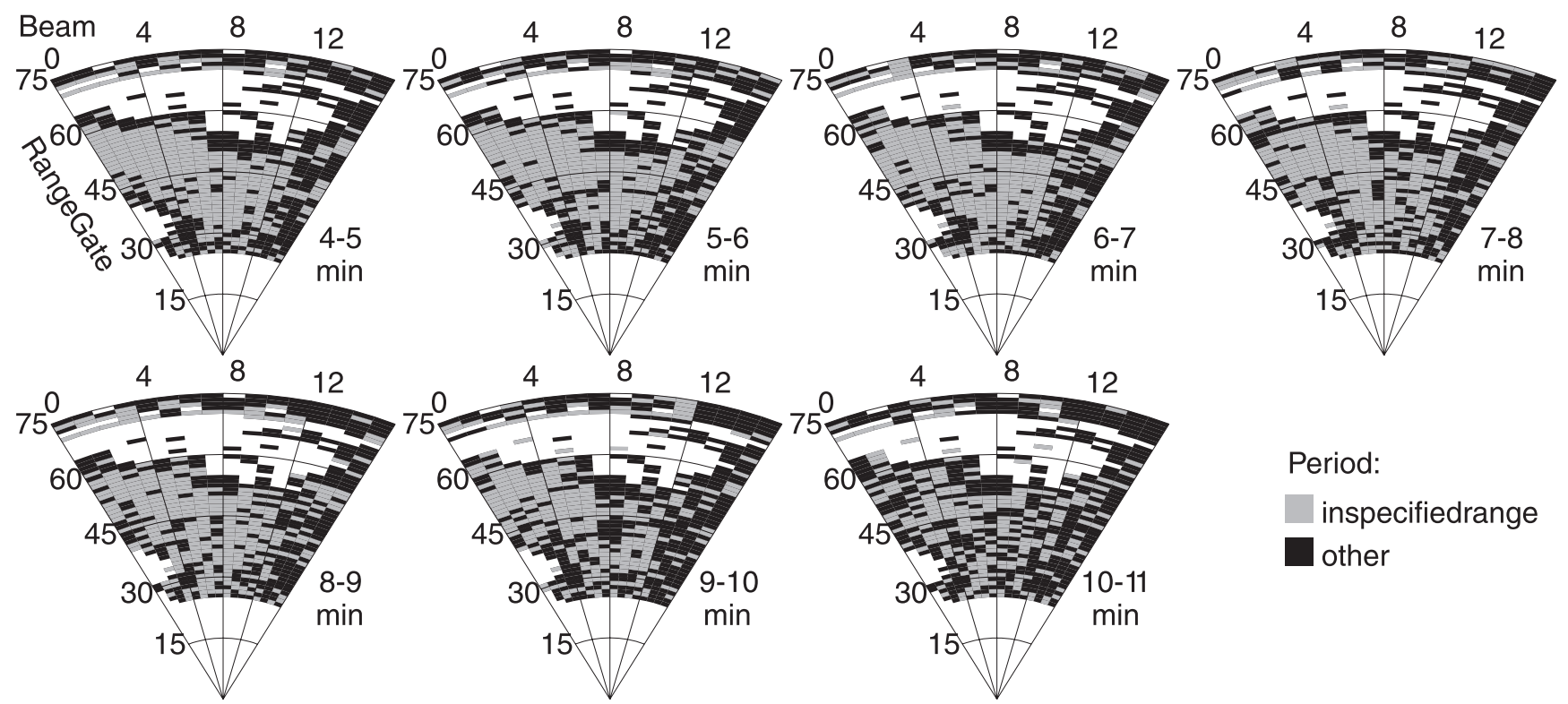

Period:

Fig. 4. Occurrence of velocity fluctuation period $T$, such that $4.0 \mathrm{~min} \leq T<5.0 \mathrm{~min}, \quad 5.0 \mathrm{~min} \leq T<6.0 \mathrm{~min}, \quad 6.0 \mathrm{~min} \leq$ $T<7.0 \mathrm{~min}$, and so on for the 09:00-13:00 UT interval on 3 January, 1996. Range cells where the FFT spectrum is calculable but there are no periods within the stated range above the

minimum power threshold are coloured black. The grey range cells are where the FFT analysis has found periods within the specified one-minute interval. A clear grouping of range cells with similar periods can be seen between range gates 30 and 60 and extending across beams 0 to 12 


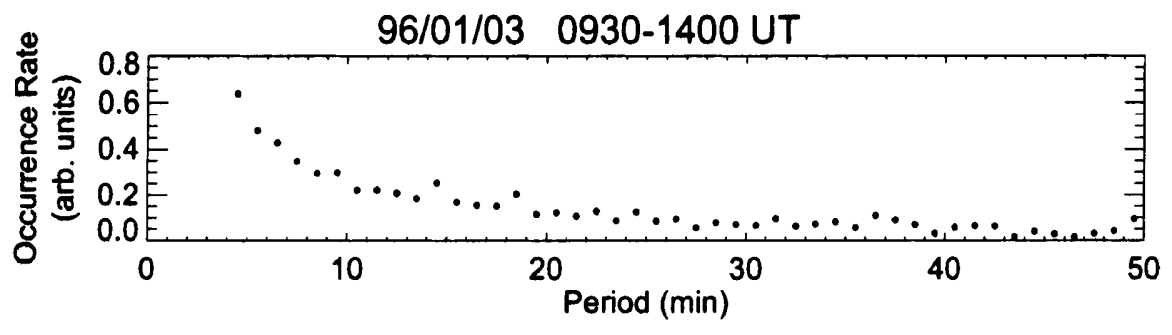

Fig. 5. The distribution of the velocity fluctuation periods from Fig. 4 for the 09:00-13:00 UT interval on 3 January, 1996, for velocity fluctuations with periods between 0 and $50 \mathrm{~min}$. The distribution has a high occurrence rate at low periods that decreases with increasing period, and is typical of the PIF intervals studied periods in the centre of the radar field of view between range gates 30 and 60 that extend across beams 0 to 12 . The grouping tended to become less obvious for higher $T$. Comparison of these plots with the LOS velocity data in Fig. 2a reveals that the grouped periodicities are found in the poleward-moving PIFs. Some intervals included in the statistical study have also shown well grouped periods in the part of the field of view believed to be sunward return flow on closed field lines. The most poleward region of PIFs in the eastern part of the field of view was not well suited to the FFT analysis. The time series in this region consisted of high speed flow bursts separated by data gaps.

For each one-minute period interval (each panel in Fig. 4), the normalised power of the significant peaks of the Fourier spectra across the field of view were added together. This gave, for each panel in Fig. 4, a quantitative estimate of the contribution of that velocity repetition period to the ionospheric convection over the whole radar field of view. For example, for beam 15, range 52 (see Fig. 3b) there were no Fourier spectral peaks with periods between 4 and $5 \mathrm{~min}$, so the total contribution for this range cell in the 4-5 min interval was zero. Between 5 and 6 min, there were two Fourier spectral peaks above the $5 \%$ minimum power threshold. Therefore the total normalised power for the 5-6 min interval is roughly 0.15 . The totals in each one-minute interval were then summed over the entire field of view. For example, contributions from all range cells for the 4-5 min interval were summed and the total was approximately 0.65 . The resulting distribution of velocity fluctuations with periods between 0 and $50 \mathrm{~min}$ is plotted in Fig. 5. In general, this distribution with a high occurrence rate at low periods that decreased with increasing period was typical of the PIF intervals studied.

\subsection{The statistics}

In order to determine which intervals were suitable for the statistical study, it was necessary to devise a quantifiable method to select the data in which the periodicities were well grouped, like the data shown in Fig. 4. The result was a simple algorithm that compared the number of range cells where periodicities existed (the grey range cells in Fig. 4) to the number of their adjacent grey neighbours. The neighbouring cells included in the calculation are those which share a side with the range cell in question; therefore each range cell has a maximum of four neighbours. The ratio of the total number of grey neighbours to the total number of grey points represents how well grouped the periodicities are within the field of view. For example, for a statistically large distribution such that edge effects can be neglected, the maximum ratio that could be obtained is 4 . Inspection showed that a ratio of 1.5 corresponds to substantial aggregation in the field of view. An interval is considered therefore to be well grouped if it has at least two one-minute period intervals with a ratio greater than 1.5. Only data further away from the radar than range gate 25 is considered, as this is the minimum range where F-region ionospheric backscatter is observed in the LOS data. Of the original 239 PIF intervals selected by hand in the common mode data set, 139 intervals, comprising $456.25 \mathrm{~h}$ of observations, survived the Fourier analysis and were well enough grouped in the radar field of view to be used in the statistical aggregation. Data from the 60 high-time resolution intervals ( $149 \mathrm{~h}$ of data) did not undergo this rigorous analysis of the grouping because usually only one beam was operating at the higher resolution. However, all high-time resolution events showed a tendency for clustering of the grey cells along the beam at the expected ranges.

\section{Discussion}

\subsection{Occurrence rates and repetition frequencies}

For each of the intervals the total contribution of each weighted periodicity in all range cells was calculated. Then a distribution over the one-minute periodicity intervals between 0 and $50 \mathrm{~min}$ was determined, like the one in Fig. 5. In order to account for the different interval durations, the occurrence rate for each distribution was multiplied by the length of the PIF interval. This periodicity histogram format was chosen to facilitate the comparison with results from in situ spacecraft and ground-based optical measurements. The results for all intervals in the statistical study were then combined to produce a histogram of the occurrence rate of the PIF period versus the period. The normalised histogram for the common mode data is coloured grey in Fig. 6a. There are no periods less than 4 min, since the sampling rate of the radar is 2 min, i.e. the Nyquist frequency is $4.2 \mathrm{mHz}$. The occurrence rate of the line of sight velocity fluctuation period decreases with increasing repetition period. The solid and dotted lines denote the normalised occurrence rate of the distributions of the inter-FTE intervals deduced from the ISEE spacecraft 


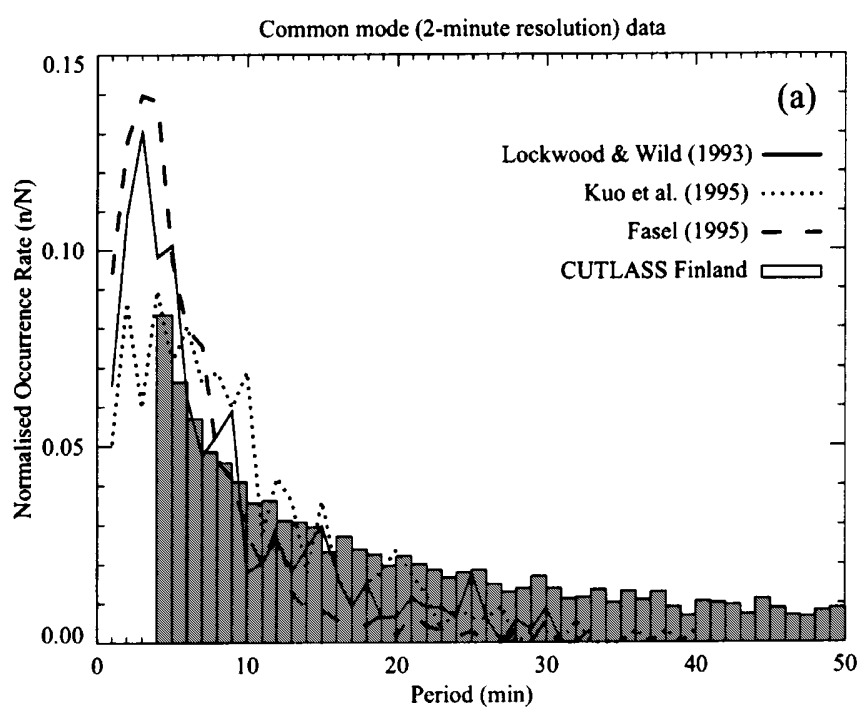

Fig. 6a, b. The occurrence rate of the line of sight velocity fluctuation period for a 2-min (common mode) and $\mathbf{b}$ high-time resolution (7 to $21 \mathrm{~s})$ CUTLASS Finland radar data. The solid and dotted lines are the distributions of inter-FTE intervals from ISEE spacecraft data

near the magnetopause in the reconnection region by Lockwood and Wild (1993) and Kuo et al. (1995), respectively. The dashed line represents the normalised occurrence rate of the time between PMAFs in optical data (Fasel, 1995). The statistical distribution of the high-time resolution radar data intervals is shown in Fig. 6b. The distribution of the common mode and high-time resolution data sets are very similar, which confirms statistically that the common mode of operation is capable of detecting PIFs, as demonstrated by Provan and Yeoman (1999). Furthermore, the similarity between the radar data, the spacecraft data, and the optical data is striking, especially considering that the measurements were taken in different regions of the magnetosphere by different instruments and that vastly different analysis techniques were employed. Because the FFTs of the LOS velocity time series include all fluctuations measured in the ionospheric plasma flows, more fluctuations may be included in the statistical distribution than just those associated with FTEs, such as longer period IMF variations or more rapidly varying ULF waves (Milan et al., 1999).

\subsection{IMF distribution}

A preliminary survey of the IMF conditions seen by the WIND magnetic field instrument during the intervals of pulsed ionospheric flows seen by the CUTLASS Finland radar reveals no dependence on the IMF $B_{y}$ component and a strong dependence on the IMF $B_{z}$ component (see Fig. 7). Of the intervals $67 \%$ occurred during southward IMF conditions, which lends support to the hypothesis that PIFs are a reconnection-related phenomenon. The IMF orientation in this study is consistent with the statistical studies of FTEs by Rijnbeek et al. (1984) and

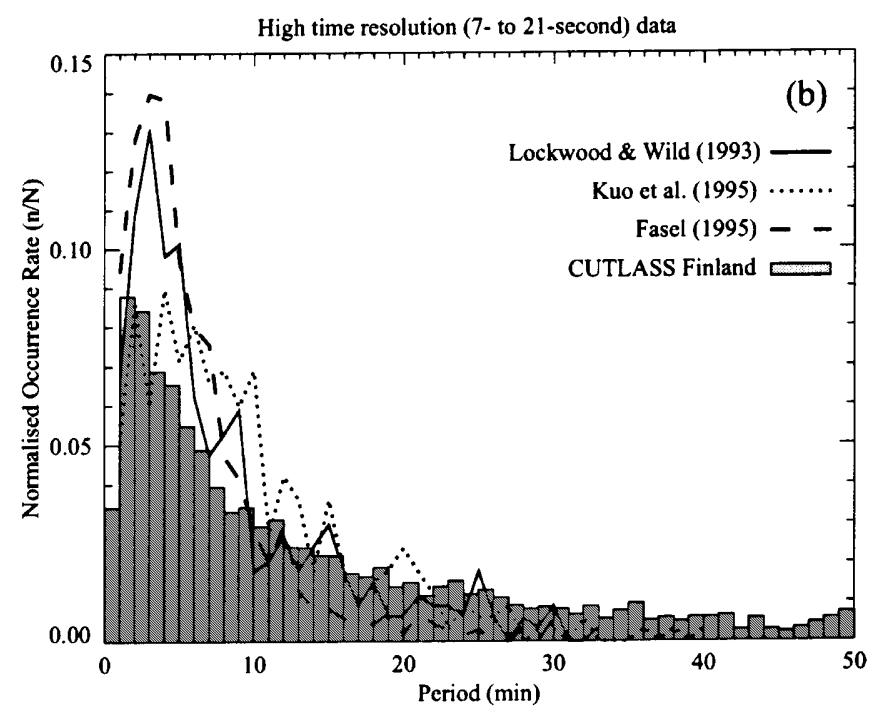

measured in the vicinity of dayside reconnection by Lockwood and Wild (1993) and Kuo et al. (1995), respectively. The dashed line is the distribution of the time between ground-based optical measurements of poleward moving auroral forms (Fasel, 1995)

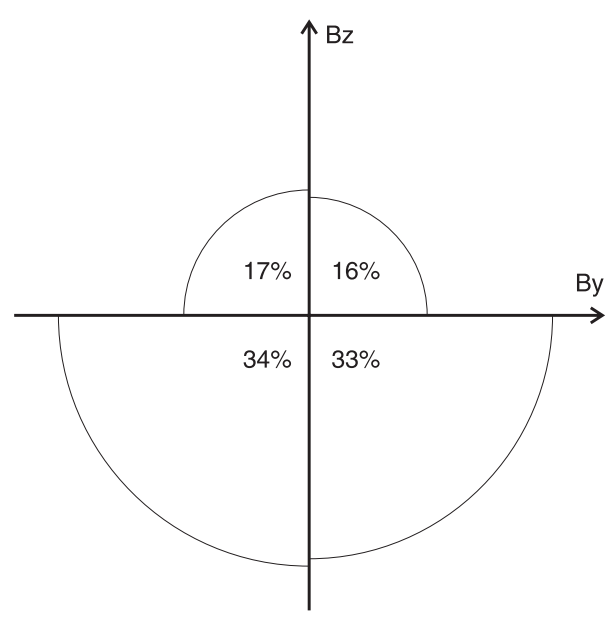

Fig. 7. The IMF $Y$ and $Z$ dependence for all PIF intervals with a clear IMF orientation that were used to deduce the occurrence rate of the transient flow periodicities used to deduce the distribution in Fig. 6. There is a strong dependence on the $B_{z}$ component, with $67 \%$ of the intervals occurring during southward IMF conditions. There is no dependence on the $B_{y}$ component of the IMF

Berchem and Russell (1984) who found a strong dependence on IMF $B_{z}$. The lack of a dependence on the IMF $B_{y}$ component contrasts with the results of Provan et al. (1998) who found a preponderance of positive IMF $B_{y}$ intervals in the radar data. A similar $B_{y}$ bias in PMAFs was reported by Sandholt et al. (1992) and was attributed to the field-aligned current orientation (Saunders, 1989). The PIF identification technique of Provan et al. (1998) relied on a visual inspection of data from only one or two radar beams in the field of view. This may have introduced some radar geometry effects. This is in contrast to the automated, quantitative technique for PIF analysis presented here, whose 
strength lies in the objective nature of the analysis of velocity fluctuations across the entire radar field of view.
The Editor in chief thanks C.T. Russell and another referee for their help in evaluating this paper.

\section{Summary}

PIFs have been established as the ionospheric electric field signature of FTEs (Goertz et al., 1985; Elphic et al., 1990; Moen et al., 1995; Yeoman et al., 1997; Neudegg et al., 1999). Two-minute and 7 to $21 \mathrm{~s} \mathrm{HF}$ radar data measured between March 1995 and September 1996 by the CUTLASS Finland radar were studied to determine the statistical distribution of the repetition frequencies of ionospheric electric field fluctuations in the footprint of the dayside magnetic reconnection region in order to make a comparison with in situ measurements of reconnection. The analysis technique was based on the Fourier transform, which was used to select the dominant repetition rates of the periodic flow bursts seen along the radar line-of-sight. The velocity fluctuations were well grouped within the field-of-view, and they were found in both the bursty poleward flow and in the sunward return flow at lower latitudes. $67 \%$ of the well-grouped PIF intervals occurred during southward IMF conditions, a strong indication that they are a reconnection-related phenomenon. No such IMF $B_{y}$ bias was observed.

The statistical distributions of the PIF repetition periods seen by CUTLASS agreed with satellite observations of the inter-FTE interval (Lockwood and Wild, 1993; Kuo et al., 1995) and optical observations of poleward moving auroral forms (Fasel, 1995). The radar, therefore, appears to give an unbiased sample of the ionospheric footprint of magnetopause activity. Caution must be used when interpreting pulsed ionospheric flows in radar, optical and other data sets in this manner, however, since other phenomena, such as ULF waves, may be responsible for the pulsed nature of the velocity data.

The statistical distributions of the PIFs seen by CUTLASS were found to be independent of the temporal resolution of the scan mode, confirming that the common mode of operation is useful for detecting pulsed flows in the cusp. High-time resolution data is preferable, however, for studying the evolution of flows. The radars have the advantage of routine observations of the cusp footprint and are therefore an extremely useful tool in the study of magnetopause activity. The analysis technique will be applied to additional SuperDARN radars to explore instrument geometry, local time, and interhemispheric effects.

Acknowledgements CUTLASS is supported by the Particle Physics and Astronomy Research Council (PPARC grant PPA/R/R/1997/ 00256), UK, the Swedish Institute for Space Physics, Uppsala, and the Finnish Meteorological Institute, Helsinki. K. McWilliams would like to thank S.E. Milan for many helpful discussions. The authors would like to thank the principal investigators R.P. Lepping and K. Ogilvie for the use of key parameter data from the WIND MFI and SWE instruments, respectively. K. McWilliams gratefully acknowledges graduate research funding from the Association of Commonwealth Universities of the British Council. G. Provan is supported by PPARC grant PPA/G/O/1997/00254.

\section{References}

Baker, K. B., J. R. Dudeney, R. A. Greenwald, M. Pinnock, P. T. Newell, A. S. Rodger, N. Mattin, and C.-I. Meng, HF radar signatures of the cusp and low-latitude boundary layer, J. Geophys. Res., 100, 7671-7695, 1995.

Berchem, J., and C. T. Russell, Flux transfer events on the magnetopause: spatial distribution and controlling factors, J. Geophys. Res., 89, 6689-6703, 1984.

Cowley, S. W. H., Solar wind control of magnetospheric convection, in Achievement of the international magnetospheric study, IMS, pp. 483, Noorwijk, Netherlands, 1984.

Cowley, S. W. H. and M. Lockwood, Excitation and decay of solar wind-driven flows in the magnetosphere-ionosphere system, Ann. Geophysicae, 10, 103, 1992.

Cowley, S. W. H., M. P. Freeman, M. Lockwood, and M. F. Smith, The ionospheric signature of flux transfer events, in Clusterdayside polar cusp, ESA SP-330, pp. 105, 1991.

Cowley, S. W. H., J. P. Morelli, M. P. Freeman, M. Lockwood, and M. F. Smith, Excitation and decay of flows in the magnetosphere-ionosphere system due to magnetic reconnection at the dayside magnetopause and in the geomagnetic tail, in Proc. International Conference on substorms, ESA SP-335, pp. 117, 1992.

Dungey, J. W., Interplanetary magnetic field and the auroral zones, Phys. Rev. Lett., 6, 47, 1961.

Elphic, R. C., M. Lockwood, S. W. H. Cowley, and P. E. Sandholt, Flux transfer events at the magnetopause and in the ionosphere, Geophys. Res. Lett., 17, 2241-2244, 1990.

Fasel, G. J., Dayside poleward moving auroral forms: a statistical study, J. Geophys. Res., 100, 11 891-11 905, 1995.

Goertz, C. K., E. Nielsen, A. Korth, K. -H. Glaßmeier, C. Haldoupis, P. Hoeg, and D. Hayward, Observations of a possible ground signature of flux transfer events, J. Geophys. Res., 90, 40694078, 1985.

Greenwald, R. A., W. Weiss, E. Nielsen, and N. R. Thomson, STARE: a new radar auroral backscatter experiment in northern Scandinavia, Radio Sci., 13, 1021-1039, 1978.

Greenwald, R. A., K. B. Baker, J. R. Dudeney, M. Pinnock, T. B. Jones, E. C. Thomas, J.-P. Villain, J.-C. Cerisier, C. Senior, C. Hanuise, R. D. Hunsucker, G. Sofko, J. Koehler, E. Nielsen, R. Pellinen, A. D. M. Walker, N. Sato, and H. Yamagishi, DARN/SuperDARN: a global view of the dynamics of high-latitude convection, Space Sci. Rev., 71, 761796, 1995.

Haerendel, G., G. Paschmann, N. Sckopke, H. Rosenbauer, and P. C. Hedgecock, The frontside boundary layer of the magnetopause and the problem of reconnection, J. Geophys. Res., 83, 3195, 1978.

Karlson, K. A., M. Øieroset, J. Moen, and P. E. Sandholt, A statistical study of flux transfer event signatures in the dayside aurora: the IMF $B_{y}$-related prenoon-postnoon asymmetry, J. Geophys. Res., 101, 59-68, 1996.

Kuo, H., C. T. Russell, and G. Lee, Statistical studies of flux transfer events, J. Geophys. Res., 100, 3513-3519, 1995.

Lepping, R. P., M. H. Acuña, L. F. Burlaga, W. M. Farrell, J. A. Slavin, K. H. Schatten, F. Mariani, N. F. Ness, F. M. Neubauer, Y. C. Whang, J. B. Byrnes, R. S. Kennon, P. V. Panetta, J. Scheifele, and E. M. Worley, The WIND magnetic field investigation, Space Sci. Rev., 71, 207-229, 1995.

Lockwood, M., Modelling the high-latitude ionosphere for timevarying plasma convection, Proc. I.E.E. (H), 140, 2, 91-100, 1993.

Lockwood, M. and M. A. Hapgood, On the cause of a magnetospheric flux transfer event, J. Geophys. Res., 103, $26453-$ $26478,1998$. 
Lockwood, M., and M. N. Wild, On the quasi-periodic nature of magnetopause flux transfer events, J. Geophys. Res., 98, 5935$5940,1993$.

Lockwood, M., P. E. Sandholt, S. W. H. Cowley, and T. Oguti, Interplanetary magnetic field control of dayside auroral activity and the transfer of momentum across the dayside magnetopause, Planet. Space Sci., 67, 1347-1365, 1989.

Lockwood, M., S. W. H. Cowley, M. F. Smith, R. P. Rijnbeek, and R. C. Elphic, The contribution of flux transfer events to convection, Geophys. Res. Lett., 22, 1185-1188, 1995.

Milan, S. E., T. K. Yeoman, M. Lester, E. C. Thomas, and T. B. Jones, Initial backscatter occurrence statistics from the CUTLASS HF radars, Ann. Geophysicae, 15, 703, 1997.

Milan, S. E., T. K. Yeoman, M. Lester, J. Moen, and P. E. Sandholt, Post-noon two-minute period pulsating aurora and their relationship to the dayside convection pattern, Ann.Geophysicae, 17, 877-891, 1999.

Moen, J., P. E. Sandholt, M. Lockwood, W. F. Denig, U. P. Løvhaug, B. Lybekk, A. Egeland, D. Opsvik, and E. Friis-Christensen, Events of enhanced convection and related dayside auroral activity, J. Geophys. Res., 23, 917-934, 1995.

Neudegg, D. A., T. K. Yeoman, S. W. H. Cowley, G. Provan, G. Haerendel, W. Baumjohann, U. Auster, K. -H. Fornacon, E. Georgescu, and C. J. Owen, A flux transfer event observed at the magnetopause by the Equator-S spacecraft and in the ionosphere by the CUTLASS HF radar, Ann. Geophysicae, 17, 707-711, 1999.

Øieroset, M., P. E. Sandholt, H. Lühr, W. F. Denig, and T. Moretto, Auroral and geomagnetic events at cusp/mantle latitudes in the prenoon sector during positive IMF By conditions: signatures of pulsed magnetopause reconnection, J. Geophys. Res., 102, 7191-7205, 1997.

Pinnock, M., A. S. Rodger, J. R. Dudeney, F. Rich, and K. B. Baker, High spatial and temporal resolution observations of the ionospheric cusp, Ann. Geophysicale, 13, 919-925, 1995.

Provan, G., and T. K. Yeoman, Statistical observations of the MLT, latitude and size of the ionospheric signature of flux transfer events with the CUTLASS Finland radar, Ann.Geophysicae, 17, 855, 1999.

Provan, G., T. K. Yeoman, and S. E. Milan, CUTLASS Finland radar observations of the ionospheric signatures of flux transfer events and the resulting plasma flows, Ann. Geophysicae, 16, 1411-1422, 1998
Provan, G., T. K. Yeoman, and S. W. H. Cowley, The influence of the IMF By component on the location of the pulsed flows in the dayside ionosphere observed by an HF radar, Geophys. Res. Lett., 26, 521-524, 1999.

Rijnbeek, R. P., S. W. H. Cowley, D. J. Southwood, and C. T. Russell, A survey of dayside flux transfer events observed by ISEE 1 and 2 magnetometers, J. Geophys. Res., 89, 786-800, 1984

Rodger, A. S., and M. Pinnock, The ionospheric response to flux transfer events: the first few minutes, Ann. Geophysicae, 15, 685$691,1997$.

Rodger, A. S., S. B. Mende, T. J. Rosenberg, and K. B. Baker, Simultaneous optical and HF radar observations of the ionospheric cusp, Geophys. Res. Lett., 22, 2045-2048, 1995.

Russell, C. T., and R. C. Elphic, Initial ISEE magnetometer results: magnetopause observations, Space Sci. Rev., 22, 681-715, 1978.

Russell, C. T., and R. C. Elphic, ISEE observations of flux transfer events at the dayside magnetopause, Geophys. Res. Lett., 6, 3336, 1979.

Sandholt, P. E., M. Lockwood, T. Oguti, S. W. H. Cowley, K. S. C. Freeman, B. Lebekk, A. Egeland, and D. M. Willis, Midday auroral breakup events and related energy and momentum transfer from the magnetosheath, J. Geophys. Res., 95, 1039-1060, 1990.

Sandholt, P. E., J. Moen, and D. Opsvik, Periodic auroral events at the midday polar cap boundary: implications of solar windmagnetosphere coupling, Geophys. Res. Lett., 19, 1223-1226, 1992.

Saunders, M. A., Origin of the cusp Birkeland current, Geophys. Res. Lett., 16, 151-154, 1989.

Siscoe, G. L., and T. S. Huang, Polar cap inflation and deflation, J. Geophys. Res., 90, 543-547, 1985.

Van Eyken, A. P., H. Rishbeth, D. M. Willis, and S. W. H. Cowley, Initial EISCAT observations of plasma convection at invariant

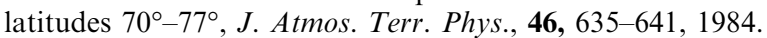

Vorobjev, V. G., G. Gustafsson, G. V. Starkov, Y. I. Feldstein, and N. F. Shevnina, Dynamics of day and night aurora during substorms, Planet. Space Sci., 23, 269-278, 1975.

Yeoman, T. K., M. Lester, S. W. H. Cowley, S. E. Milan, J. Moen, and P. E. Sandholt, Simultaneous observations of the cusp in optical, DMSP and HF radar data, Geophys. Res. Lett., 24(17), 2251-2254, 1997. 